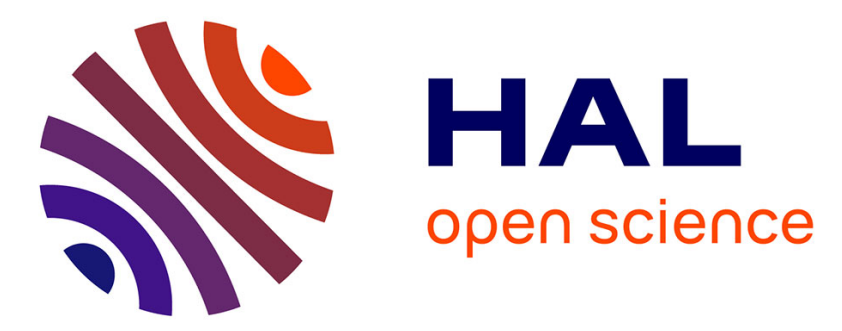

\title{
Preparation of aqueous anionic poly-(urethane-urea) dispersions: Influence of the nature and proportion of the urethane groups on the dispersion and polymer properties
}

Vanessa Durrieu, Alessandro Gandini, Mohamed Naceur Belgacem, Anne Blayo, Gilles Eiselé, Jean-Luc Putaux

\section{To cite this version:}

Vanessa Durrieu, Alessandro Gandini, Mohamed Naceur Belgacem, Anne Blayo, Gilles Eiselé, et al. Preparation of aqueous anionic poly-(urethane-urea) dispersions: Influence of the nature and proportion of the urethane groups on the dispersion and polymer properties. Journal of Applied Polymer Science, 2004, 94 (2), pp.700-710. 10.1002/app.20933 . hal-02108821

\section{HAL Id: hal-02108821 \\ https://hal.science/hal-02108821}

Submitted on 24 Apr 2019

HAL is a multi-disciplinary open access archive for the deposit and dissemination of scientific research documents, whether they are published or not. The documents may come from teaching and research institutions in France or abroad, or from public or private research centers.
L'archive ouverte pluridisciplinaire HAL, est destinée au dépôt et à la diffusion de documents scientifiques de niveau recherche, publiés ou non, émanant des établissements d'enseignement et de recherche français ou étrangers, des laboratoires publics ou privés. 


\section{OATAO \\ Open Archive Toulouse Archive Ouverte}

\section{Open Archive Toulouse Archive Ouverte (OATAO)}

OATAO is an open access repository that collects the work of Toulouse researchers and makes it freely available over the web where possible

This is an author's version published in: http://oatao.univ-toulouse.fr/ 23694

Official URL: https://doi.org/10.1002/app.20933

\section{To cite this version:}

Durrieu, Vanessa and Blayo, Anne and Eiselé, Gilles and Putaux, Jean-Luc Preparation of aqueous anionic poly-(urethane-urea) dispersions: Influence of the nature and proportion of the urethane groups on the dispersion and polymer properties. (2004) Journal of Applied Polymer Science, 94 (2). 700-710. ISSN 0021-8995

Any correspondence concerning this service should be sent to the repository administrator: tech-oatao@listes-diff.inp-toulouse.fr 


\title{
Preparation of Aqueous Anionic Poly-(urethane-urea) Dispersions: Influence of the Nature and Proportion of the Urethane Groups on the Dispersion and Polymer Properties
}

\author{
Vanessa Durrieu, ${ }^{1}$ Alessandro Gandini, ${ }^{1}$ Mohamed Naceur Belgacem, ${ }^{1}$ Anne Blayo, ${ }^{1}$ \\ Gilles Eiselé, ${ }^{2}$ and Jean-Luc Putaux ${ }^{3}$ \\ ${ }^{1}$ Ecole Française de Papeterie et des Industries Graphiques (INPG), BP 65, 38402 St. Martin d'Hères, France \\ ${ }^{2}$ SICPA S.A., BP 50674105 Annemasse Cedex, France \\ ${ }^{3}$ CERMAV-CNRS, BP 53, 38041 Grenoble Cedex, France
}

DOI 10.1002/app.20933

\begin{abstract}
Aqueous poly(urethane-urea) dispersions were prepared by the prepolymer mixing technique without the use of any organic solvent. Most of the work focused on the use of two aliphatic diisocyanates $\left(\alpha, \alpha, \alpha^{\prime}, \alpha^{\prime}\right.$-tetramethyl-1,3-xylylene diisocyanate and isophorone diisocyanate) and two macrodiols ( $\alpha, \omega$-poly(propylene glycol) $(\mathrm{Mn}$ $=1000)$ and $\alpha, \omega$-poly(caprolactone) $(\mathrm{Mn}=530)$ ) in conjunction with a fixed proportion of emulsifying agent (dimethylol propionic acid, neutralized with triethyl amine) and the same chain extender (1,2-ethylene diamine). The properties of both the dispersions and the dried polymer films, as well as those of some model prepolymers, were characterized as
\end{abstract}

a function of the initial composition to establish criteria leading to the optimized performance in terms of dispersion stability and particle size and polymer properties. The most important parameter in this search was found to be the $[\mathrm{NCO}] /[\mathrm{OH}]$ ratio, which gave the best results when it approached a value of 2. (c) 2004 Wiley Periodicals, Inc. J Appl Polym Sci 94: 700-710, 2004

Key words: poly(urethane-ureas); aqueous dispersions; oligoester and oligoether diols; aromatic and aliphatic diisocyanates; particle size; stability

\section{INTRODUCTION}

The continuous need for reductions in both production costs and volatile organic compound emissions has speared an intense activity of research on the development of water-based polymer systems, particularly for coating and adhesive formulations. Aqueous polyurethane dispersions (PUD) constitute one of the major families of such materials ${ }^{1-5}$ because of their remarkable properties, which have led to successful industrial applications. Most of the investigations related to PUDs were confined to a confidential industrial context, but recent scientific publications have provided interesting information on various aspects of both the synthetic stages and the properties of the ensuing dispersions. ${ }^{4}$

The aim of the present study is similar to that of the work carried out by Price and co-workers ${ }^{4}$ (and was indeed conducted in parallel) in terms of both synthetic approach (two-stage prepolymer mixing process) ${ }^{6}$ and the search for relationships between prep-

Correspondence to: M. N. Belgacem (Naceur.Belgacem@ efpg.inpg.fr). aration parameters and properties of the ensuing dispersions and solid polymers. However, on one hand, no organic solvent was used at any stage in our procedures and, on the other hand, the emphasis of our study was placed on the role of moieties surrounding the urethane groups and on their frequency along the polymer chain, with respect to the urea functions. The structure of the diisocyanate used plays an important role in the properties of the ensuing polymer. Thus, a symmetric molecular structure will favor: ${ }^{7}$ (i) the polymer capacity to crystallize; (ii) the separation of the microphases; and (iii) the increase of the mechanical properties, including the elastic modulus, the tensile strength, and the resistance to abrasion. Additionally, the presence of aromatic moieties will result in a higher rigidity of the final polymer. Finally, given the substantial difference in reactivity between aromatic and aliphatic isocyanates, their competitive condensation with water versus amines in the second stage of the preparation can influence the course of this chain extension.

The $\mathrm{NCO} / \mathrm{OH}$ molar ratio determines the molecular weight of the prepolymer in the first stage of the synthesis and consequently the relative proportion of the urethane and urea groups in the final polymer chain. As an ultimate result, this ratio will therefore 


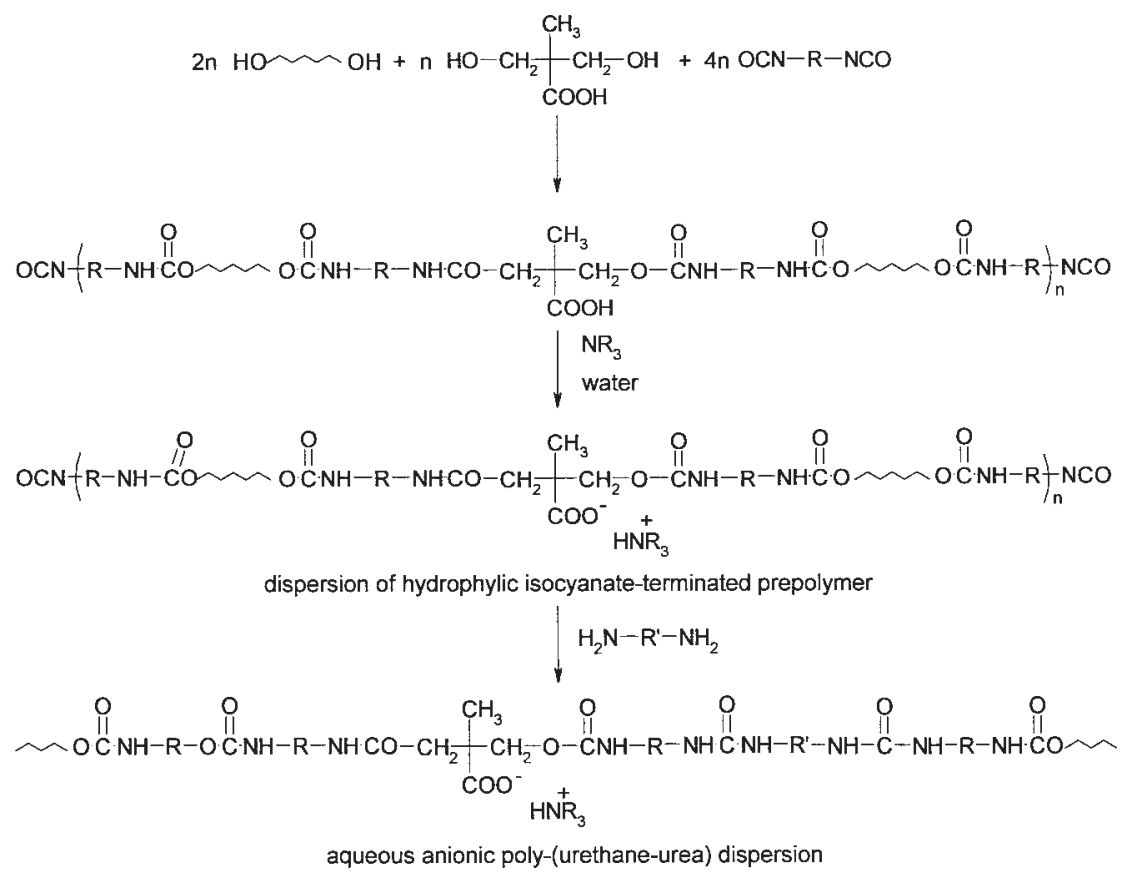

Scheme 1

affect both the properties of the dispersions, such as particle size, and the dry polymer thermal and mechanical properties.

The present article deals with numerous PUD formulations, used with variable $\mathrm{NCO} / \mathrm{OH}$ ratios and involving three aliphatic and an aromatic diisocyanates, two diols, a single diamine, and the same anionic emulsifying agent. The characterization of both the aqueous dispersions and the dry polymers enabled the establishment of criteria related to the various compositions used to prepare them.

\section{EXPERIMENTAL}

\section{Materials}

The following commercial reagents were used without further purification: 1,4,1',4'-diphenylmethane diisocyanate (MDI, Bayer, containing a small amount of the 1,3-derivative), $\alpha, \alpha, \alpha^{\prime}, \alpha^{\prime}$-tetramethyl-1,3-xylylene diisocyanate (TMXDI, Cytec), isophorone diisocyanate (IPDI, Bayer), 1,4,1', 4' -dicyclohexylmethane diisocya-

TABLE I

Surface Tension, Polar and Dispersive Contributions, and Acid-Base Characteristics $\left(\mathrm{mJ} / \mathrm{m}^{2}\right)$ of the Liquid Probes Used in This Study

\begin{tabular}{lcccccc}
\hline & $\gamma^{\mathrm{T}}$ & $\gamma^{\mathrm{D}}$ & $\gamma^{\mathrm{P}}$ & $\gamma^{\mathrm{LW}}$ & $\gamma^{+}$ & $\gamma^{-}$ \\
\hline Water & 72.8 & 21.8 & 51.0 & 21.8 & 25.5 & 25.5 \\
Glycerol & 63.4 & 37.0 & 26.4 & - & - & - \\
Formamide & 58.2 & 39.5 & 18.7 & 39.2 & 2.3 & 39.6 \\
Diodomethane & 50.8 & 48.5 & 3.3 & - & - & - \\
Hexadecane & 27.5 & 27.5 & 0.0 & 27.5 & 0.0 & 0.0 \\
\hline
\end{tabular}

nate $\left(\mathrm{H}_{12} \mathrm{MDI}\right.$, Bayer, mixture of boat/chair stereoisomers), $\alpha, \omega$-poly(propylene glycol) (PPG, $\mathrm{Mn}=1000$, Shell), $\alpha, \omega$-poly(caprolactone) (PCL, Mn $=530$, Daicel), containing two oxyethylene central groups, dimethylol propionic acid (DMPA, Perstorp), dibutyltin dilaurate (DBTL, Aldrich), triethyl amine (TEA, Acros), and 1,2-ethylene diamine (EDA, Acros). The high purity, functionality, and molecular weight of all these products were verified by spectroscopic techniques and vapor pressure osmometry.

\section{Synthesis}

\section{Prepolymer formation}

The synthesis of the polyurethane anionomers was carried out in bulk, without any intervention of an organic solvent using the "prepolymer mixing pro-

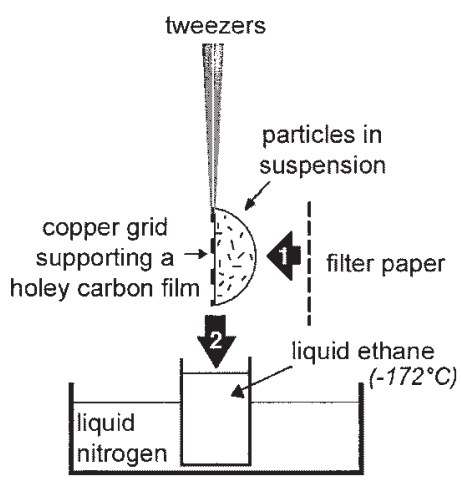

Figure 1 Principle of the fast-freezing protocol to prepare thin vitrified specimens for cryo-TEM. 


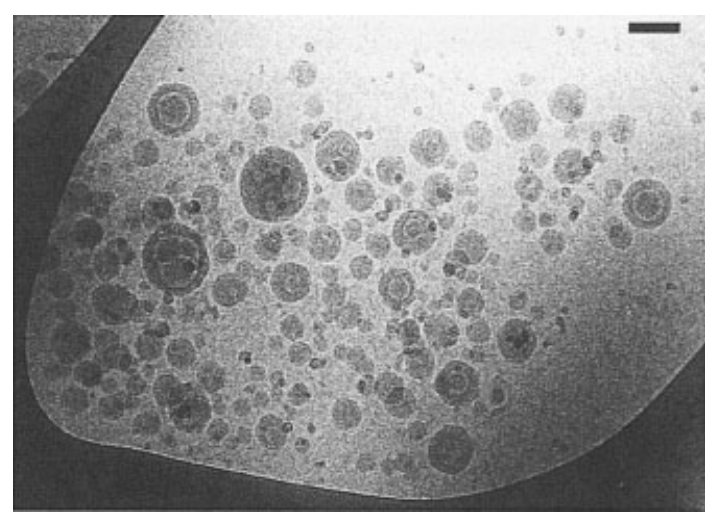

Figure 2 Cryo-TEM image of nanoparticles prepared from $\mathrm{H}_{12} \mathrm{MDI}$ and PPG 1000 (scale bar: $100 \mathrm{~nm}$ ).

cess." This first step in the preparation of dispersion called upon the successive additions of DBTL, the diol, and DMPA to the diisocyanate in an inert atmosphere at a temperature of 80 to $100^{\circ} \mathrm{C}$, under mechanical stirring at $280 \mathrm{rpm}$. In the present study, only the $\mathrm{NCO} / \mathrm{OH}$ ratio was varied, as discussed below, whereas the amount of DMPA was kept constant. The duration of this reaction depended critically on the time needed to reach the calculated value of the residual NCO concentration, which was determined by the standard dibutyl amine back titration method ASTM D 2572 and varied between 1 and $2 \mathrm{~h}$.

\section{Dispersion in water and chain extension}

Once the prepolymer had reached the final expected NCO content, it was slowly poured into an aqueous TEA solution kept at $25-30^{\circ} \mathrm{C}$ and stirred at $280 \mathrm{rpm}$. The amount of TEA was calculated so as to ensure the complete neutralization of the carboxylic group of DMPA, more specifically in a $20 \%$ molar excess. Immediately after the completion of this addition, the chain extender (EDA) was introduced slowly (to avoid a sudden increase in viscosity, which would interfere with the formation of the good dispersion) and thereafter stirring was increased to $500 \mathrm{rpm}$ and the medium was left to react (chain extension) for $90 \mathrm{~min}$.

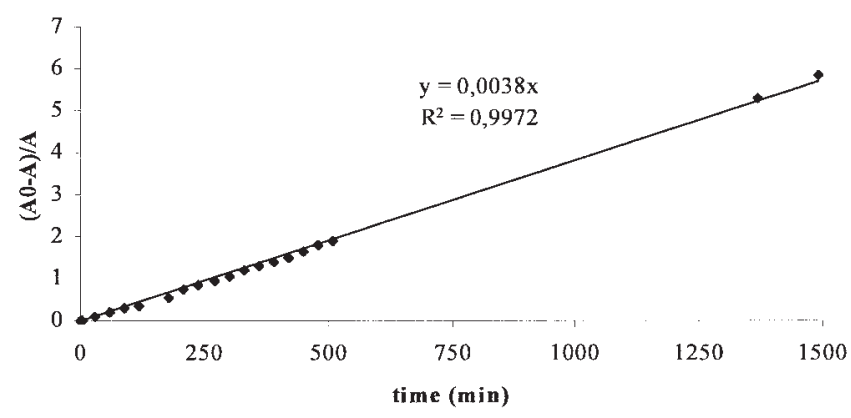

Figure 3 Second-order plot for the reaction of ethanol and TMXDI.

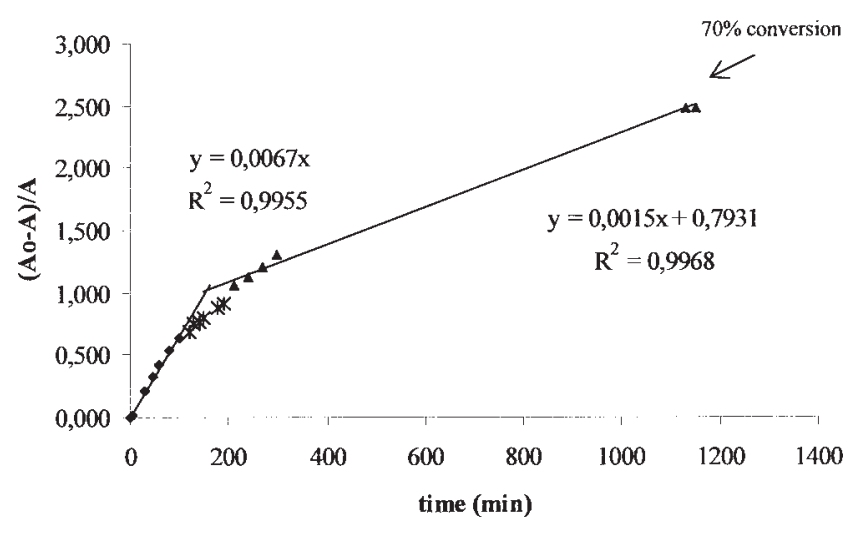

Figure 4 Second-order plot for the reaction of ethanol and IPDI.

The quantity of EDA added was calculated to obtain a 1:1 NCO: $\mathrm{NH}_{2}$ stoichiometry.

The ensuing aqueous polyurethane-urea dispersions were characterized by a solid content of about $30 \% \mathrm{w} / \mathrm{w}$. Scheme 1 summarizes the different mechanistic steps involved in the overall preparation of these dispersions.

\section{Characterization}

The aqueous dispersions were spread on a Teflon mold and dried to a constant weight in an oven at $60^{\circ} \mathrm{C}$. FTIR and ${ }^{1} \mathrm{H}-\mathrm{NMR}$ spectra were taken with a Perkin-Elmer Paragon 1000 and a Bruker 300 instrument, respectively. The thermal analyses (DSC and TGA) were carried out using a Setaram DSC-TGA 92 calorimeter with a heating rate of $10^{\circ} \mathrm{C} / \mathrm{min}$. The values given as degradation temperature in the text correspond to the temperature at which the sample lost $10 \%$ of its initial weight. GPC tracings were obtained with a Spectra Physics chromatograph equipped with two calibrated columns. Polymers were dissolved in a DMF-(0.1 M) $\mathrm{NaNO}_{3}$ solution at a concentration of 1 $\mathrm{g} / \mathrm{L}$.

Static and dynamic contact angles on the polymer films were measured with a homemade goniometer equipped with a CDD camera working at up to 200 images $/ \mathrm{s}^{8}$ The results were collected in a video card and treated with image analysis software. Among the different approaches enabling the determination of the different contributions to the surface energy of the solid based on contact angle measurements, ${ }^{9}$ we chose

TABLE II

Second-Order Rate Constants and Domains of Validity

\begin{tabular}{|c|c|c|c|}
\hline \multirow[b]{2}{*}{ Diisocyanate } & \multicolumn{2}{|c|}{$k(\mathrm{~kg} / \mathrm{mol} . \mathrm{s})$} & \multirow[b]{2}{*}{ Domain of validity (\%) } \\
\hline & $k_{1}$ & $k_{2}$ & \\
\hline TMXDI & \multicolumn{2}{|c|}{0.095} & 85 \\
\hline IPDI & 0.16 & 0.038 & 71 \\
\hline
\end{tabular}




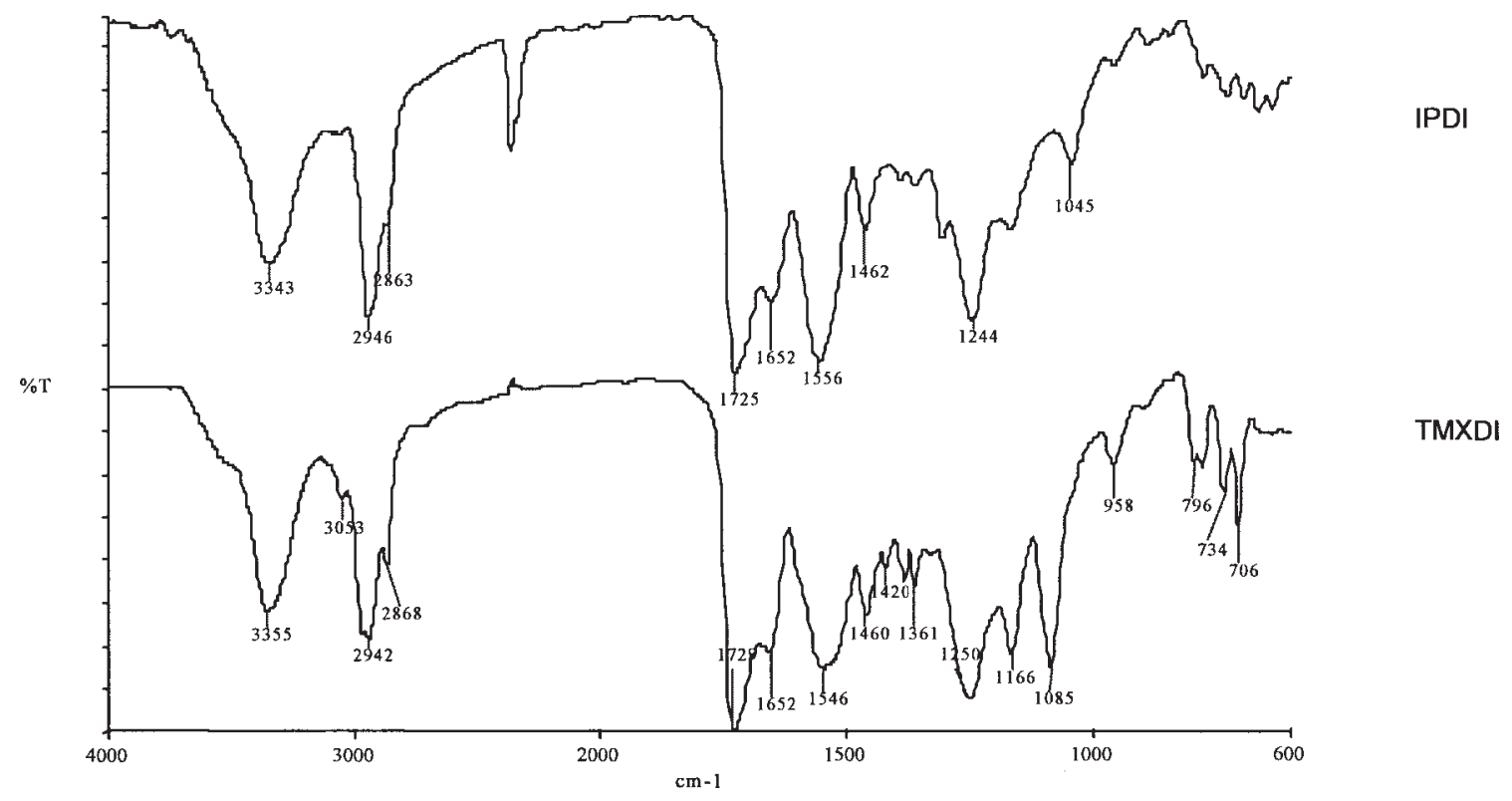

Figure 5 FTIR spectra of PUDs prepared with PCL and the indicated diisocyanate.

to work with the two most common ones, i.e., those proposed by Owens and Wendt and van Oss. The Owens-Wendt treatment is a refinement of Fowkes' approach to the polar and dispersive contribution to surface tension. The resulting equation is

$$
W_{\mathrm{SL}}=\gamma_{\mathrm{L}}(1+\cos \theta)=2 \sqrt{\gamma_{\mathrm{L}}^{\mathrm{d}} \gamma_{\mathrm{S}}^{\mathrm{d}}}+2 \sqrt{\gamma_{\mathrm{L}}^{\mathrm{p}} \gamma_{\mathrm{S}}^{\mathrm{p}}}
$$

where $W_{\mathrm{SL}}$ is the energy of adhesion, $\gamma_{\mathrm{L}}$ is the liquid surface tension, $\theta$ is the contact angle, $\gamma_{\mathrm{L}}^{1}, \gamma_{\mathrm{L}}^{\mathrm{P}}$ are the dispersive and polar contributions to the liquid surface tension and $\gamma_{S}^{1}, \gamma_{S}^{p}$ are the dispersive and polar contributions to the solid surface energy.

Thus, plotting the term $\gamma_{\mathrm{L}}(1+\cos \theta) / \sqrt{\gamma_{\mathrm{L}}^{\mathrm{d}}}$ as a function of $\sqrt{\gamma_{\mathrm{L}}^{\mathrm{p}}} / \sqrt{\gamma_{\mathrm{L}}^{\mathrm{d}}}$, it is possible to determine $\gamma_{\mathrm{S}}^{1}$ from the intercept and $\gamma_{S}^{\mathrm{p}}$ from the slope. Table I gives the surface tension of the liquids we used in terms of their polar and dispersive contribution.

Van Oss' approach takes into account the acid-base interactions between the solid surface and the liquid drop, through the equation

$$
\begin{aligned}
& W_{\mathrm{SL}}=\gamma_{\mathrm{L}}(1+\cos \theta)=\gamma^{\mathrm{LW}}+\gamma^{\mathrm{AB}} \\
& =2 \sqrt{\gamma_{\mathrm{S}}^{\mathrm{LW}} \gamma_{\mathrm{L}}^{\mathrm{LW}}}+2 \sqrt{\gamma_{\mathrm{L}}^{+} \gamma_{\mathrm{S}}^{-}}+2 \sqrt{\gamma_{\mathrm{L}}^{-} \gamma_{\mathrm{S}}^{+}},
\end{aligned}
$$

here:

$\gamma^{\mathrm{LW}}$ is the Lifshitz-Van der Waals contribution,

$\gamma^{\mathrm{AB}}$ is the acid-base contribution,

$\gamma^{+}$is the acid contribution, and

$\gamma^{-}$is the basic contribution to the surface energy.

Table I gives the corresponding contribution related to the five liquids we used in this context.

The observation of the suspended polymer particles in the poly(urethane-urea) dispersions was conducted using transmission electron cryomicroscopy. Thin vitrified films were prepared with a Leica EM CPC fastfreezing apparatus. A drop of highly diluted suspension was deposited on a commercial "lacey" carbon film (PELCO). The excess liquid was blotted out with a filter paper. Before evaporating the remaining fluid, the grids were quenched-frozen by liquid ethane cooled with liquid nitrogen at $-171^{\circ} \mathrm{C}$ (Fig. 1). ${ }^{10}$ The

\begin{tabular}{|c|c|c|c|c|c|c|}
\hline & & \multirow[b]{3}{*}{ Diisocyanate } & \multicolumn{4}{|c|}{ Diol } \\
\hline & & & \multicolumn{2}{|c|}{ PPG $(r=2)$} & \multicolumn{2}{|c|}{ PCL $(r=1.8)$} \\
\hline & & & TMXDI & IPDI & TMXDI & IPDI \\
\hline Glass transition temperature & ${ }^{\circ} \mathrm{C}$ & & -3 & -38 & 68 & 36 \\
\hline \multirow[t]{2}{*}{ Degradation temperature } & ${ }^{\circ} \mathrm{C}$ & & 305 & 310 & 310 & 325 \\
\hline & $\mathrm{mJ} / \mathrm{m}^{2}$ & $\gamma^{\mathrm{D}}$ & 21.7 & 17.6 & 19.2 & 17.7 \\
\hline \multirow[t]{2}{*}{ Surface energy (Owens-Wendt method) } & $\mathrm{mJ} / \mathrm{m}^{2}$ & $\gamma^{\mathrm{P}}$ & 17.6 & 18.8 & 20.5 & 20.5 \\
\hline & $\mathrm{mJ} / \mathrm{m}^{2}$ & $\gamma^{T}$ & 39.3 & 36.4 & 39.7 & 38.2 \\
\hline Surface energy (Van Oss method) & $\mathrm{mJ} / \mathrm{m}^{2}$ & $\gamma^{T}$ & 38.5 & 37.0 & 39.0 & 38.2 \\
\hline
\end{tabular}

TABLE III

Effect of the Diisocyanate Structure on the Properties of the Final Polymers 
TABLE IV

Effect of the Diisocyanate Structure on the Properties of Aqueous Dispersions

\begin{tabular}{llrrrrr}
\hline & & \multicolumn{3}{c}{ Diol } \\
\cline { 3 - 4 } & & & \multicolumn{2}{c}{ PPG $(r=2)$} & & PCL $(r=1.8)$ \\
\cline { 3 - 4 } & Diisocyanate & TMXDI & IPDI & & TMXDI & IPDI \\
\hline pH & & 7.7 & 8.2 & 8.0 & 9.1 \\
Surface tension & $\mathrm{mJ} / \mathrm{m}^{2}$ & 38.8 & 39.2 & & 47.8 & 42.9 \\
Average particle size & $\mathrm{Nm}$ & 35.6 & 34.7 & & 101.1 & 72.1 \\
$\zeta$ potential & $\mathrm{MV}$ & -40.2 & -40.7 & & -36.7 & -39.0 \\
\hline
\end{tabular}

sample was then transferred into a Gatan 626 cryoholder kept at $-180^{\circ} \mathrm{C}$ with liquid nitrogen and observed at a magnification of $11,500 \times$, using a Philipps CM200 cryomicroscope operating at a voltage of $80 \mathrm{kV}$. Pictures were recorded with an underfocus of about 1 $\mu \mathrm{m}$, using a Philipps Low Dose system, which allows the imaging conditions to be set up near the area of interest, to protect it from any irradiation prior to photographic exposure. ${ }^{11,12}$ Negatives of the micrographs were digitized using a Kodac Megaplus CDD camera. Contrast enhancement and particle measurements were performed by NH-Image and optimas software.

The average particle size measurements of the aqueous dispersions were performed by light scattering with a Malvern Autosizer 2c.

The $\zeta$ potential of these particles was measured by their electrophoretic mobility with a Malvern Zetasizer 2000.

The surface tension of the dispersions was determined using a digital tensiometer K10ST (Krüss) working with a Du Nouy platinum ring, whereas their viscosity was measured with a Carri-Med CSL ${ }^{2} 500$ cone-plate rheometer using a fixed stress and working in a flow mode at a constant temperature $\left( \pm 0.1^{\circ} \mathrm{C}\right)$. For the sake of comparison, all viscosities given below were taken at a shear rate equal to $500 \mathrm{~s}^{-1}$.

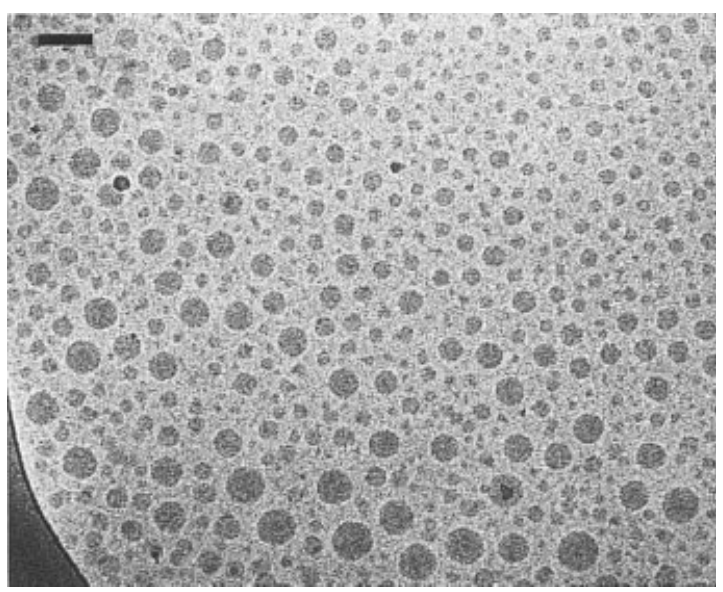

Figure 6 Cryo-TEM image of nanoparticles prepared from PPG and TMXDI (scale bar: $100 \mathrm{~nm}$ ).

\section{RESULTS AND DISCUSSION}

Although they are more expensive and require a catalyst, aliphatic diisocyanates are generally preferred to their aromatic homologues for the preparation of polyurethane dispersions because: (i) they have low reactivity, particularly with respect to water; (ii) they enable the preparation of prepolymers at higher temperatures $\left(100-120^{\circ} \mathrm{C}\right.$ against $60-80^{\circ} \mathrm{C}$ for aromatic counterparts); (iii) they yield prepolymers with lower viscosity, which are therefore easier to disperse in water; and (iv) the NCO groups are not directly conjugated to a double bond, which confers a better light and aging resistance to the corresponding poly(urethane-ureas). However, in the present study, it was decided to compare their performances with that of MDI, viz. the aromatic diisocyanate most commonly used in solvent-based polyurethanes, but also in some aqueous polyurethane dispersions.

\section{Effect of the diisocyanate structure}

MDI

The reaction of MDI + PPG + DMPA gave a highly viscous product and was marred by the fact that DMPA was not totally solubilized. During the dispersion step, a gel formed, certainly because of the excessively high reactivity of the aromatic NCO groups, which promoted

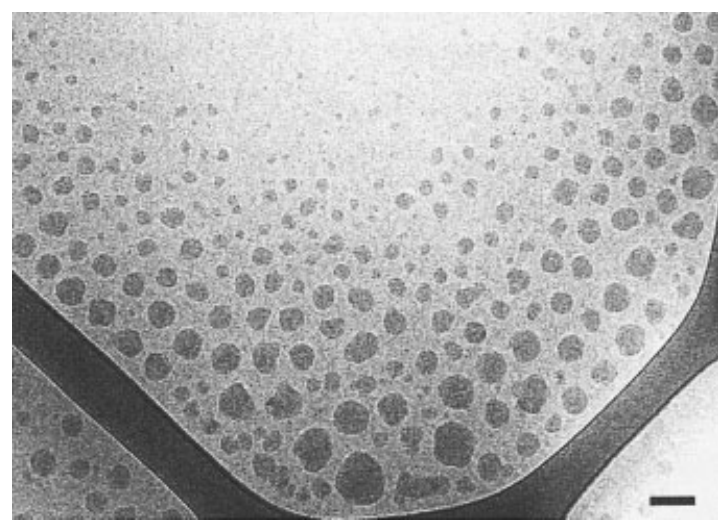

Figure 7 Cryo-TEM image of nanoparticles prepared from PPG and IPDI (scale bar: $100 \mathrm{~nm}$ ). 


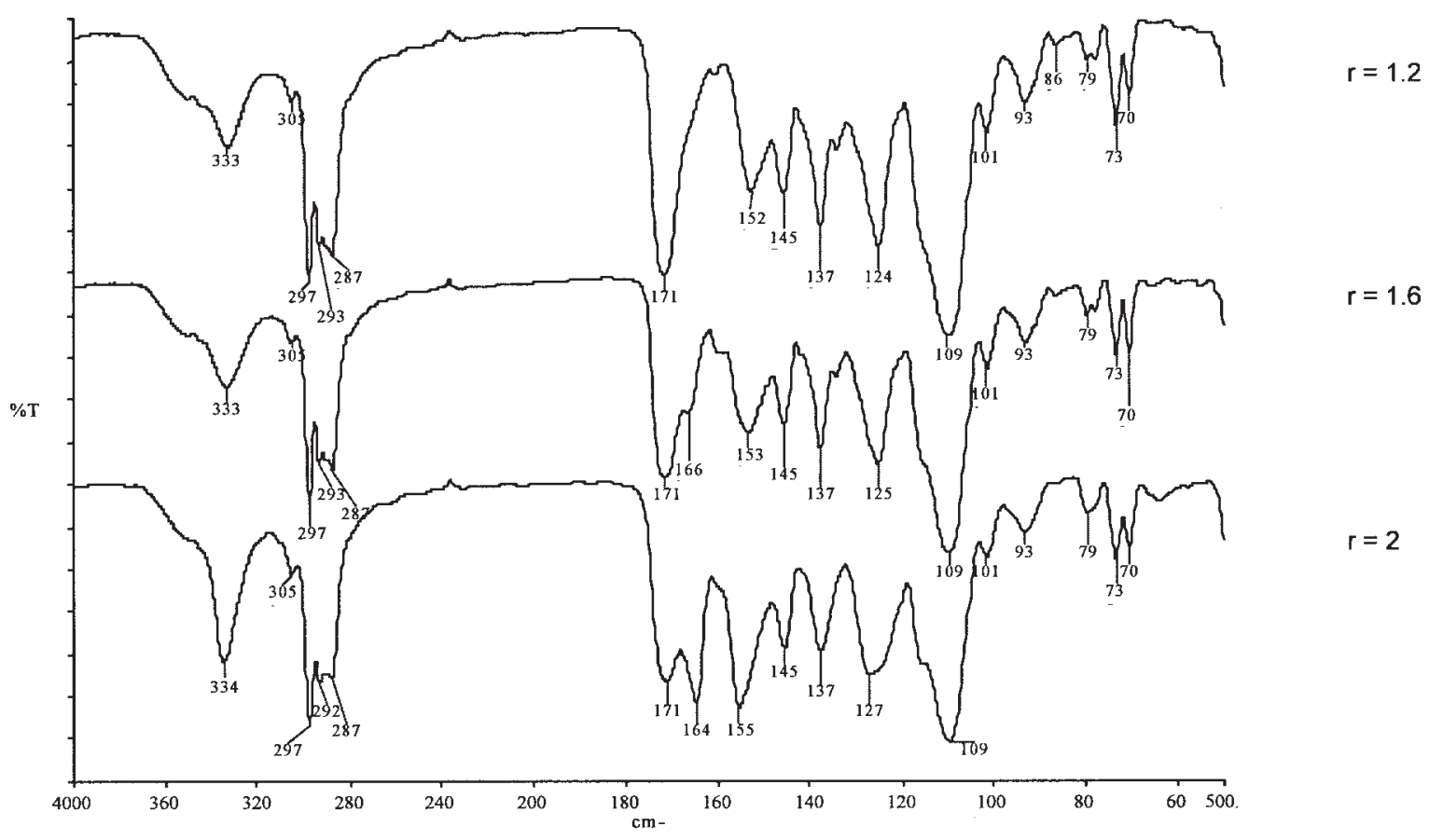

Figure 8 FTIR spectra of prepolymers prepared with PPG and TMXDI, at different [NCO]/[OH] ratios, and neutralized with $t$-butylamine.

their side reaction with already formed urethane moieties, to give allophonate branching and eventually the formation of a polymer network. Moreover, during the dispersion step, some of the NCO groups would have reacted with water, thus increasing the number of urea linkages to the detriment of chain extension.

These results confirmed the unsuitability of aromatic isocyanates for the preparation of aqueous PUD dispersions, at least with the present procedure, which did not call upon the use of organic solvents. Indeed, the use of MDI has been reported for aqueous dispersions, but only in the "so-called" acetone process, ${ }^{13}$ in which both the prepolymer synthesis and the chain extension take place in organic solvent (so that the $\mathrm{NCO}$ functions can not react with water), before dispersion of the ensuing polymer solution in water.

\section{HMDI}

The prepolymer synthesis and the chain extension were carried out without any difficulty, but the final dispersion was not homogeneous and was unstable with time since a phase separation appeared with storage time. The characterization of these dispersions by cryomicroscopy gave evidence of particle encapsulation, as shown in Figure 2. This phenomenon was attributed to both the diisocyanate symmetry and the diol structural regularity, which would favor the formation of crystalline microphases in the prepolymer, enabling further reaction during the chain extension. Thus, if only the amorphous portions of the prepolymer could react with a chain extender, the resulting macromolecules would surround the inactive crystalline portions and generate the microcapsules. This morphology probably prevented an adequate distribution of the ionic moieties, which would explain the instability of the dispersion with time.

\section{IPDI and TMXDI}

To assess the relative reactivity toward $\mathrm{OH}$ functions of the NCO groups of these two diisocyanates, we studied the kinetics of their condensation with ethanol in dry acetone at room temperature. The initial concentration of both functions was $410^{-2} \mathrm{M}$ and the reactions were followed by the decrease of the infrared NCO peak at $2250 \mathrm{~cm}^{-1}$.

With TMXDI, a good second-order behavior was obtained as shown in Figure 3, indicating that the two NCO functions displayed equal reactivity, as indeed expected because of the symmetry of the molecule bearing them. With IPDI, the asymmetric emplacement of the two NCO groups gave rise to two secondorder regimes as shown in Figure 4. The faster initial reaction dominated up to $40 \%$ conversion and was

TABLE V

Effect of the $[\mathrm{NCO}] /[\mathrm{OH}]$ Ratio on the Prepolymer Properties

\begin{tabular}{lrcc}
\hline Diisocyanate & TMXDI & \\
[NCO]/[OH] ratio & 2 & 1.6 & 1.2 \\
Glass transition temperature $\left({ }^{\circ} \mathrm{C}\right)$ & -30 & -27 & -24 \\
Viscosity at $80^{\circ} \mathrm{C}$ (mPa.s) & 577 & 231 & 78 \\
\hline
\end{tabular}


TABLE VI

Spectral Characterizations of the Diurea Crystals

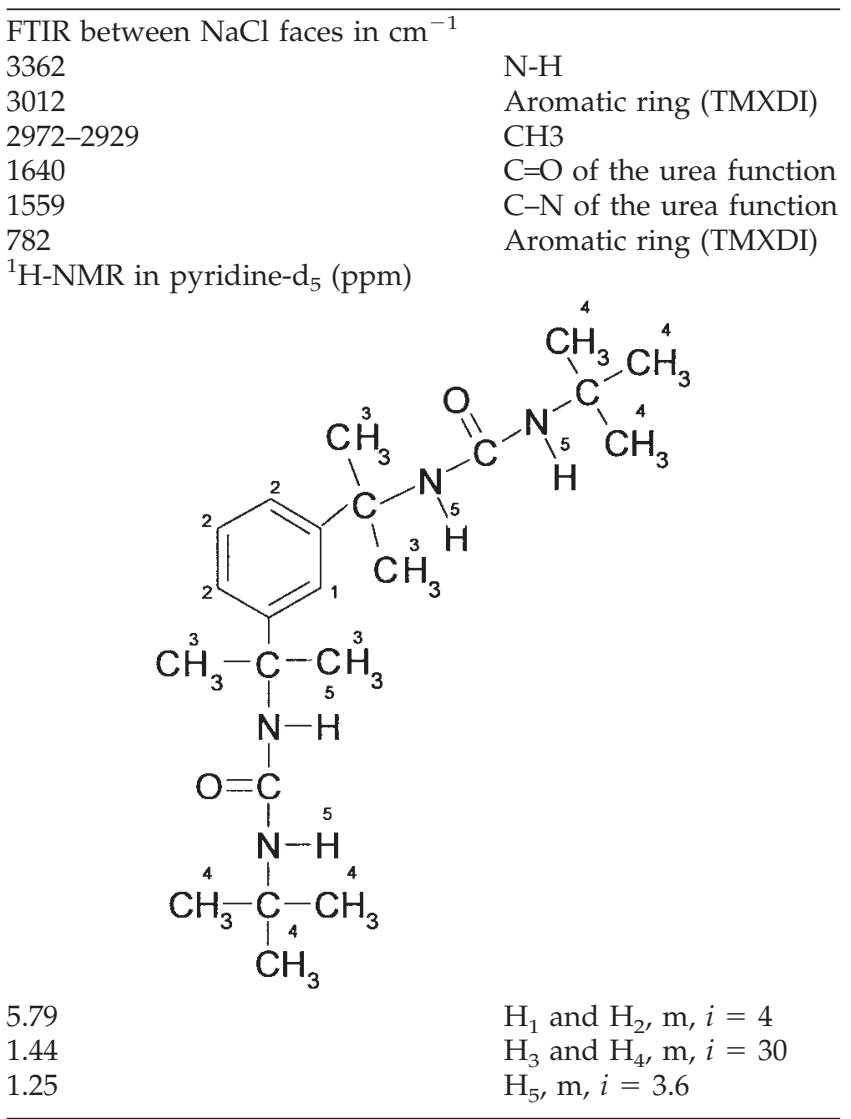

followed by a transition zone, leading to a slower second-order behavior starting at about 50\% conversion. Table II gives the second-order rate constants corresponding to these kinetic studies. The reactivity of the TMXDI NCO groups was found to be intermediate between those of the two different counterparts attached to IPDI. We attribute the highest reactivity to the IPDI NCO attached to the methylene groups because of its lower steric screening and the higher reactivity of TMXDI NCO, compared with the second isocyanate group of IPDI, to its long-range activation by the aromatic ring.

These results suggest that in the context of the preparation of PUD, IPDI was globally more reactive than TMXDI (particularly when using $\mathrm{NCO} / \mathrm{OH}$ close to 2) during the prepolymer formation, whereas the $\mathrm{NCO}$ reactivity was reversed during the chain extension step.

\section{Comparison between IPDI and TMXDI structures}

The structures of the final polymers obtained from these two diisocyanates and the two macrodiols used in this study were examined by FTIR and ${ }^{1} \mathrm{H}-\mathrm{NMR}$ spectroscopy, which displayed all the features related to regular linear poly(urethane-ureas). Figure 5 shows an example of two FTIR spectra of polymers prepared with the same macrodiol (PCL, Mn = 530) and the two aliphatic diisocyanates, the $\mathrm{NCO} / \mathrm{OH}$ ratio was kept constant $(r=1.8)$. The common peaks were associated with relevant urethane, urea, and polycaprolactone moieties and differences were assigned essentially to the presence of the aromatic ring of TMXDI (bands at 3053 and 1085 and between 700 and $800 \mathrm{~cm}^{-1}$ ).

The characterization of the four polymers arising from these combinations, using $\mathrm{NCO} / \mathrm{OH}$ ratios $(r$ close to 2) is given in Table III. With both diols the glass transition temperature was higher when TMXDI

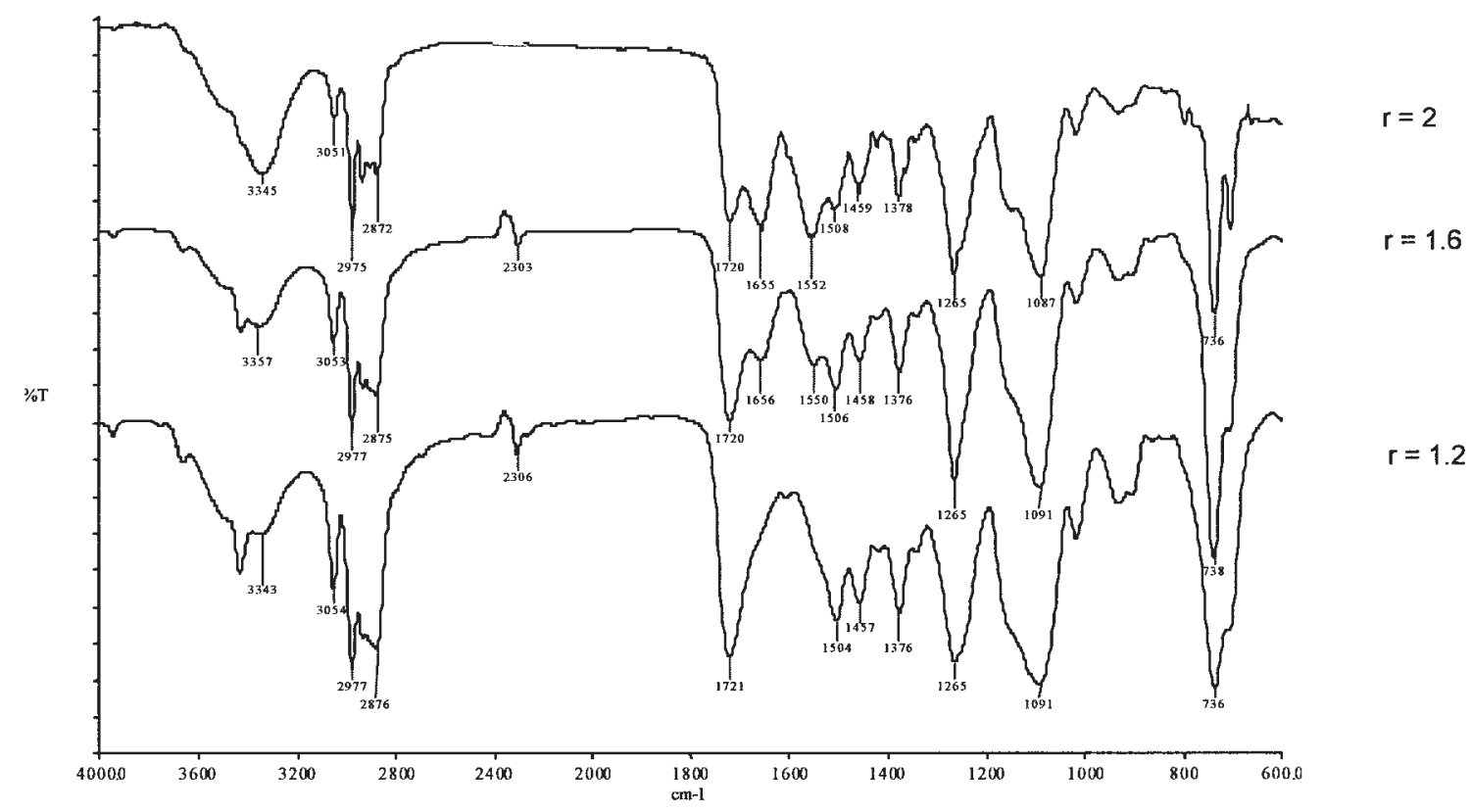

Figure 9 FTIR spectra of polymers based on PPG and TMXDI at different $[\mathrm{NCO}] /[\mathrm{OH}]$ ratios and chain extended with EDA. 


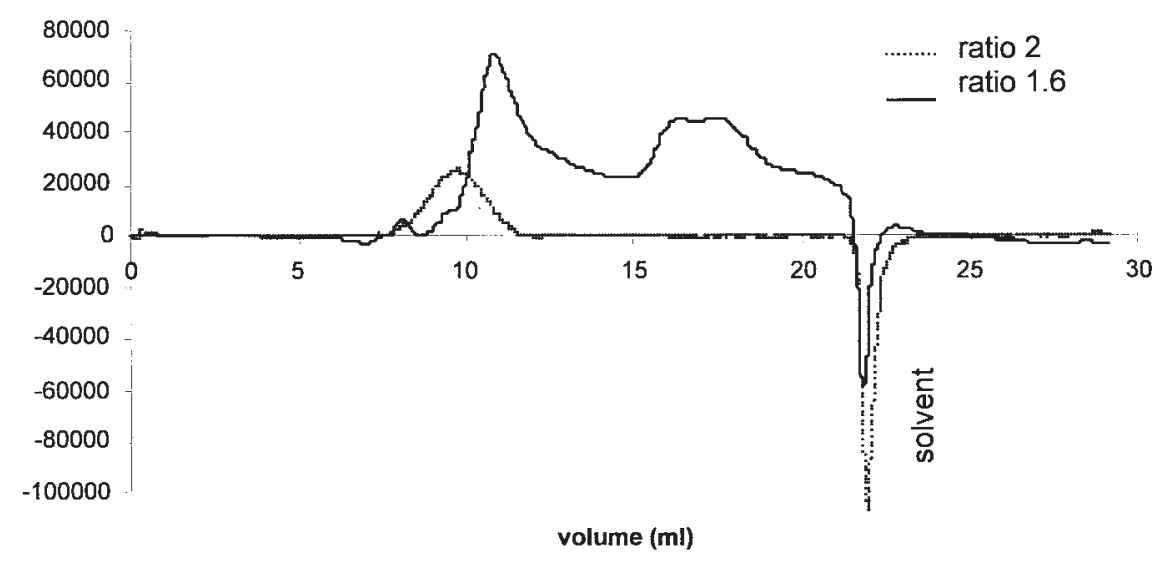

Figure 10 GPC tracings of two polymers based on PPG and TMXDI ( $r=1.6$ or 2$)$ and chain extended with EDA.

was used, given the enhanced polymer stiffness associated with its aromatic ring. Conversely, the thermal stability was higher with IPDI-based polymers, probably because of its totally aliphatic structure. ${ }^{7}$ The values of the total surface energy were very similar among the four polymers and moreover the two different determination techniques gave concordant results. A modest difference was found in the values of the polar contribution in favor of the TMXDI-based polymer, which was attributed to the aromatic ring $\pi$-bonds.

The properties of the corresponding four aqueous dispersions are given in Table IV. As expected, no significant variations were encountered in terms of $\mathrm{pH}$ (essentially determined by the excess TEA added in the neutralization step), surface tension (independent of the polymer structure), and $\zeta$ potential (which is directly related to the negative charge density on the polymer chains, which was kept constant through the constant amount of DMPA). The only parameter that was sensitive to the specific changes in the conditions applied to these four combinations was the average particle size. The major differences occurred when the macrodiol was changed, since the use of PCL induced a substantial increase in particle size. We interpreted this trend on the basis of the higher hydrophobic character of this structure with respect to that associated with propylene oxide units, which would enhance water repellence at the dispersion stage and thus limit the extent of polymer fragmentation. The nature of the diisocyanate did not play a detectable role on particle size when PPG was used, whereas with PCL, TMXDI produced a moderate increase with respect to IPDI. It seems that with the higher hydrophobic systems based on PCL, the structure of the diisocyanate can also intervene. Here, the increase in particle size associated with the use of TMXDI was attributed to its higher molecular stiffness compared with that of IPDI.

It can be concluded that the structure of the diisocyanate can affect significantly the course of the synthesis, the stability of the ensuing dispersions, and the properties of the final polymers, without intervening, in a major way, with modification on the other properties of the aqueous dispersions.

The cryomicroscopy images revealed that the actual shape of the particles depended on the structure of the diisocyanate used, as shown in Figures 6 and 7. In fact, whereas the particles obtained from dispersions based on TMXDI were on average very nearly spherical, the shape of the counterparts prepared with IPDI was more irregular, most probably because of the softer

TABLE VII

Effect of the $[\mathrm{NCO}] /[\mathrm{OH}]$ Molar Ratio on the Polymer Properties

\begin{tabular}{|c|c|c|c|c|c|c|c|c|c|c|c|}
\hline & & \multirow[b]{3}{*}{$r$} & \multicolumn{9}{|c|}{ Diisocyanate } \\
\hline & & & \multicolumn{5}{|c|}{ TMXDI } & \multicolumn{4}{|c|}{ IPDI } \\
\hline & & & 2 & 1.8 & 1.6 & 1.4 & 1.2 & 2 & 1.8 & 1.6 & 1.4 \\
\hline Glass transition temperature & ${ }^{\circ} \mathrm{C}$ & & -3 & -26 & -28 & -31 & -34 & -38 & -43 & -44 & -48 \\
\hline Degradation temperature & ${ }^{\circ} \mathrm{C}$ & & 305 & 305 & 295 & 270 & - & 310 & 315 & - & 295 \\
\hline \multicolumn{12}{|l|}{ Surface energy } \\
\hline \multirow[t]{3}{*}{ (Owens-Wendt method) } & $\mathrm{mJ} / \mathrm{m}^{2}$ & $\gamma^{\mathrm{D}}$ & 21.7 & 19.7 & 17.4 & 15.6 & 14.3 & 17.6 & 16.3 & 14.2 & 13.0 \\
\hline & $\mathrm{mJ} / \mathrm{m}^{2}$ & $\gamma^{\mathrm{P}}$ & 17.6 & 17.7 & 19.2 & 19.1 & 18.2 & 18.8 & 17.8 & 19.3 & 19.3 \\
\hline & $\mathrm{mJ} / \mathrm{m}^{2}$ & $\gamma^{\mathrm{T}}$ & 39.3 & 37.4 & 36.5 & 34.7 & 32.6 & 36.4 & 34.1 & 33.5 & 32.3 \\
\hline \multirow{2}{*}{$\begin{array}{l}\text { Surface energy } \\
\text { (Van Oss method) }\end{array}$} & & & & & & & & & & & \\
\hline & $\mathrm{mJ} / \mathrm{m}^{2}$ & $\gamma^{\mathrm{T}}$ & 38.5 & 37.8 & 36.7 & 34.8 & 33.0 & 37 & 35.7 & 34.3 & 31.7 \\
\hline
\end{tabular}




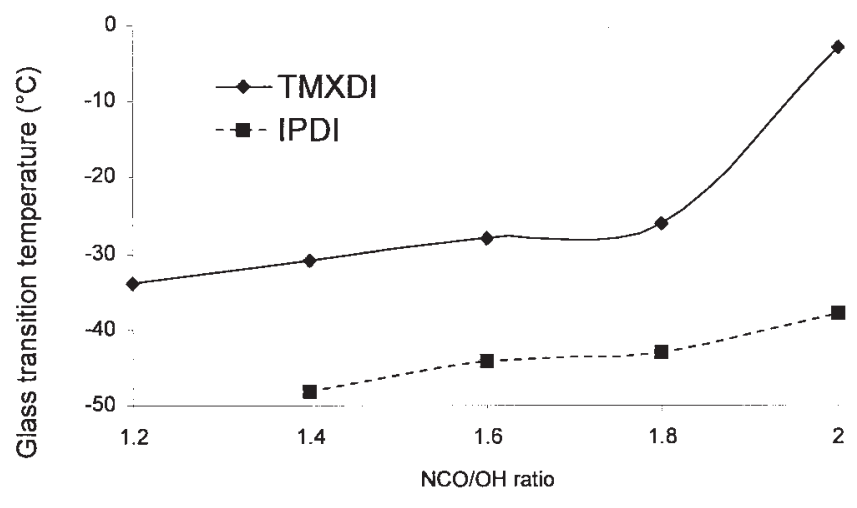

Figure 11 Effect of $r$ on the glass transition temperatures of different isolated polymers (see Table VII).

character of the PU containing the latter, i.e., the more flexible molecular structures, which facilitated particle deformation under shear at the dispersion stage.

\section{Effect of the $[\mathrm{NCO}] /[\mathrm{OH}]$ molar ratio}

This parameter is mostly responsible for the variations in the prepolymer molecular weight and its relative content of urethane and urea groups. To assess its role on the properties of both aqueous emulsions and final polymers, we studied three systems based on TMXDI and PPG in which its value varied between 1.2 and 2.0, respectively, (corresponding to average DPn of 11 to 3). In a first approach, we carried out only the synthesis of three prepolymers, with $r=1.2,1.6$, and 2, in the presence of DMPA, as indicated under Experimental, and neutralized the terminal NCO groups with an excess of $t$-butylamine, to simulate the chemistry of the chain extension process without actually increasing the molecular DP. The ensuing products were isolated and characterized. Figure 8 shows the FTIR spectra of these three materials, which give the expected identical qualitative features related to the moieties arising from each monomer and those associated with the formation of urethane and terminal urea groups. The relevant quantitative differences among these spectra arose from the increasing proportion of terminal urea groups, associated with the corresponding decrease on the DP, which are clearly visible in the peaks around $3340(\mathrm{~N}-\mathrm{H}), 1650(\mathrm{C}=\mathrm{O})$, and 1530 $\mathrm{cm}^{-1}(\mathrm{C}-\mathrm{N})$. Table $\mathrm{V}$ gives the glass transition temperatures and the viscosity of these prepolymers. The changes in $T_{\mathrm{g}}$ were modest, but in the right direction, viz. an increase with increasing DP. The presence of two opposing structural trends explained the modest increase, namely a decrease in interchain hydrogen bond (stiffening effect) as a function of increasing DP, counterbalanced by the classical increase in $T_{\mathrm{g}}$ associated with oligomer chain length. In the case of the viscosity values (which were obtained at $80^{\circ} \mathrm{C}$ because of the high consistency of these prepolymers), the intermolecular cohesive forces generated by the hydrogen bonding among urea terminal groups (which were the larger the lower the DP) dominated largely over the opposite effect associated with a viscosity increase with increasing chain length. This difference in behavior is understandable, because the flow properties of oligomers are primarily determined by the extent of intermolecular interactions, whereas $T_{\mathrm{g}}$ is less sensitive to these interactions and more affected by chain length.

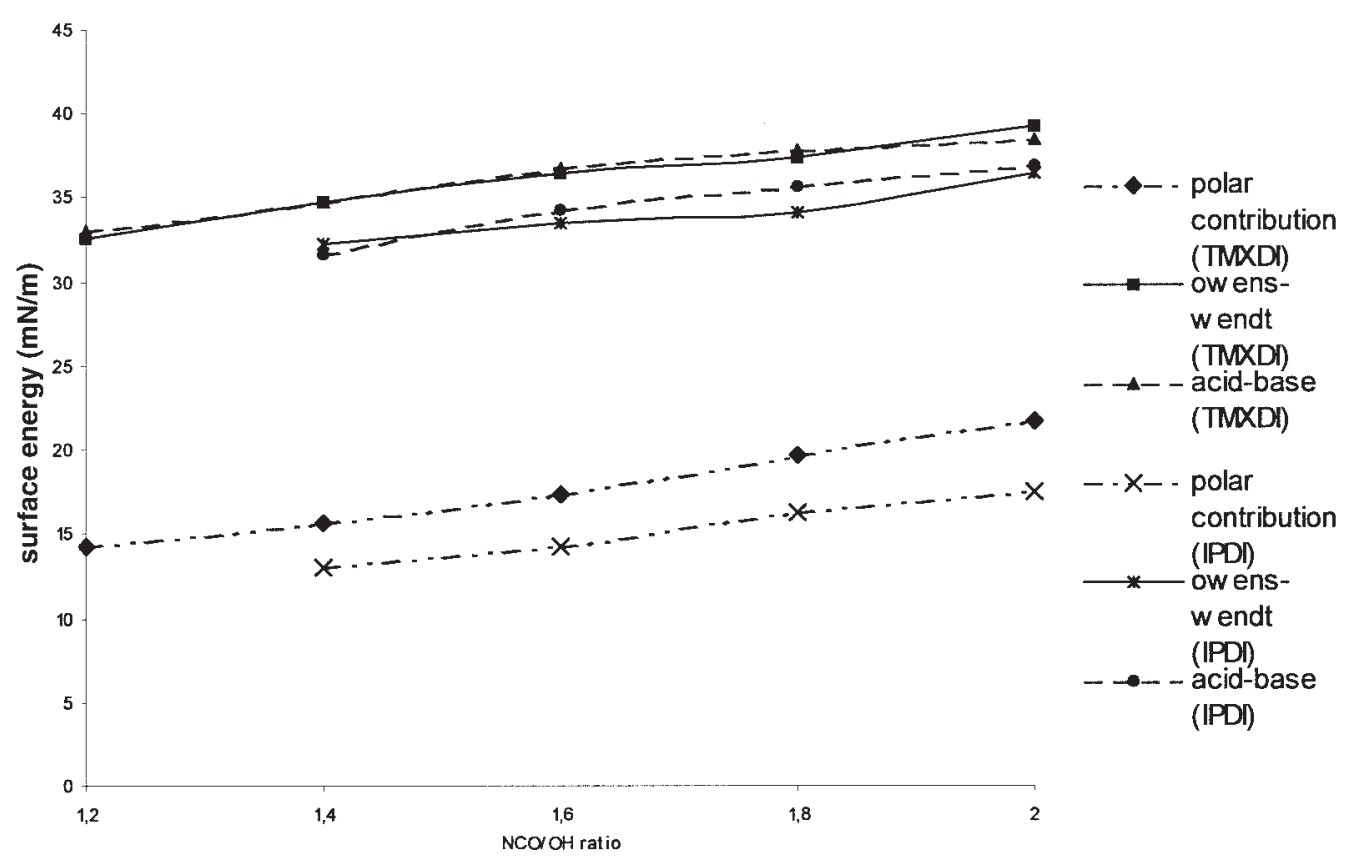

Figure 12 Effect of the $[\mathrm{NCO}] /[\mathrm{OH}]$ ratio on the surface energy of polymer films (see Table VII). 
TABLE VIII

Effect of the $[\mathrm{NCO}] /[\mathrm{OH}]$ Ratio on the Properties of Different Dispersions

\begin{tabular}{|c|c|c|c|c|c|c|c|c|c|c|}
\hline & \multirow[b]{3}{*}{$r$} & \multicolumn{8}{|c|}{ Diisocyanate } & \\
\hline & & \multicolumn{5}{|c|}{ TMXDI } & \multicolumn{4}{|c|}{ IPDI } \\
\hline & & 2 & 1.8 & 1.6 & 1.4 & 1.2 & 2 & 1.8 & 1.6 & 1.4 \\
\hline $\mathrm{pH}$ & & 7.7 & 9.0 & 8.8 & 7.5 & 8.1 & 8.2 & 9.3 & 8.3 & 7.5 \\
\hline Surface tension & $\mathrm{mJ} / \mathrm{m}^{2}$ & 38.8 & 38.6 & 38.2 & 37.4 & 38.7 & 39.2 & 37.8 & 37.3 & 38.5 \\
\hline Average particle size & $\mathrm{nm}$ & 35.6 & 52.2 & 75.4 & 79.3 & 83.7 & 34.7 & 46.2 & 57.3 & 71.1 \\
\hline$\zeta$ potential & $\mathrm{mV}$ & -40.2 & -39.5 & -37.4 & -36.1 & -38.7 & -40.7 & -39.1 & -45.3 & -41.7 \\
\hline Viscosity & MPa.s & 47.5 & 56.1 & 78.2 & 33.7 & 14.4 & 91.9 & 96.3 & 52.5 & 18 \\
\hline
\end{tabular}

A crystalline product insoluble in the bulk of the viscous oligomers was produced in the experiments carried out with $r=2$. It was characterized by FTIR and NMR spectroscopy and shown unambiguously (Table VI) to be the $t$-butylamine diurea of TMXDI.

We then proceeded to prepare several dispersions using DMPA at a fixed content and TMXDI or IPDI in variable proportions. Thus, instead of blocking the $\mathrm{NCO}$ end groups of the prepolymers of a monoamine, we carried out the chain extension with EDA, as already described.

Figure 9 compares the FTIR spectra of three of the isolated polymers (prepared with PPG $(\mathrm{Mn}=1000)$ and TMXDI) as a function of $r$. As in the case of the urea terminated prepolymer, the urea $\mathrm{N}-\mathrm{H}, \mathrm{C}=\mathrm{O}$, and $\mathrm{C}-\mathrm{N}$ peaks increased markedly with increasing excess of NCO, to the detriment of the corresponding bands pertaining to the urethane moieties.

As expected, the molecular weight of these polymers increased with decreasing value of $r$ and their distribution widened. Figure 10 shows a comparison of GPC tracings of two of these products, which illustrate the above trend. The narrow distribution associated with $r=2$ is particularly relevant since the chain extension was accomplished in this case starting with a prepolymer of an average DP of 3 and therefore a very sharp size distribution.

The other relevant properties of these polymers are given in Table VII. With both isocyanates, the glass transition temperature increased with increasing $r$ values (Fig. 11), indicating that now the determining parameter was the proportion of strong H-bonding arising from the corresponding increasing proportion of urea moieties. In other words, interchain cohesive energy factors played a more important role than molecular weight.

The thermal stability of these polymers showed a slight improvement with increasing urea moiety content, confirming previous results, which showed systematically that these functions resist better than urethane ones against thermal treatment. ${ }^{7}$

Finally, the surface energy of these polymer films gave the same values, as measured by the two methods. Whereas the dispersive contribution remained essentially constant in terms of both the diisocyanate used and the value of $r$, the polar contribution increased regularly as $r$ increased, indicating that the urea functions displayed a higher polarity than their urethane counterparts. All these features are clearly displayed in Figure 12.

Table VIII gives the characterization of the corresponding dispersions. Once again their $\mathrm{pH}$, surface tension, and $\zeta$ potential were not significantly affected by the change in diisocyanate and the variation in the $[\mathrm{NCO}] /[\mathrm{OH}]$ ratio. These observations are in tune with the fact that as long as the nature, the quantity, and the total neutralization of the emulsifying agent are unchanged, there is no reason justifying any variation in those properties.

On the other hand, the average particle size was significantly affected by the changes in the values of $r$ in that an increase of this ratio produced a corresponding decrease in particle size with both diisocyanates (Fig. 13). This trend was related to the higher hydrophilic properties of the urea moieties compared with those of their urethane counterpart. It can be concluded that the introduction of a higher proportion of urea groups by increasing the $[\mathrm{NCO}] /[\mathrm{OH}]$ ratio can play a similar role as that of the emulsifying agent in favoring a decrease in the average particle size.

In general, a decrease in the average particle size produces a corresponding increase in the viscosity of

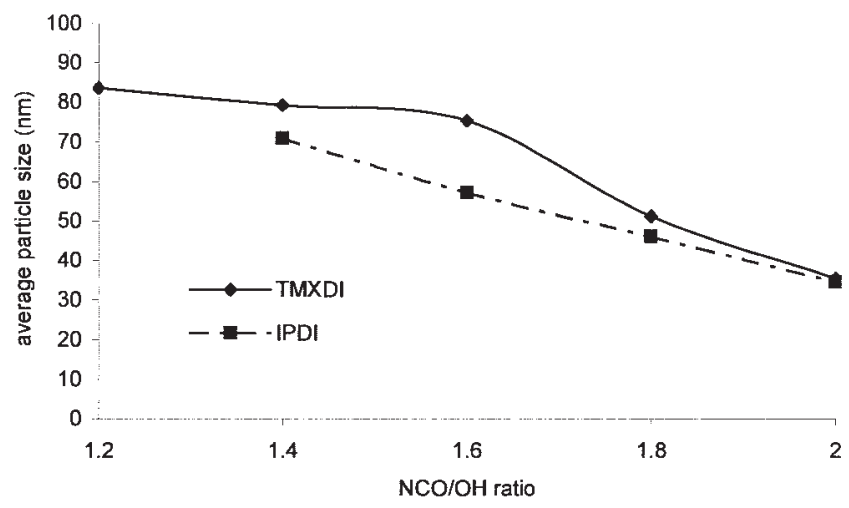

Figure 13 Effect of $[\mathrm{NCO}] /[\mathrm{OH}]$ ratio on the average particle size of dispersions (see Table VIII). 


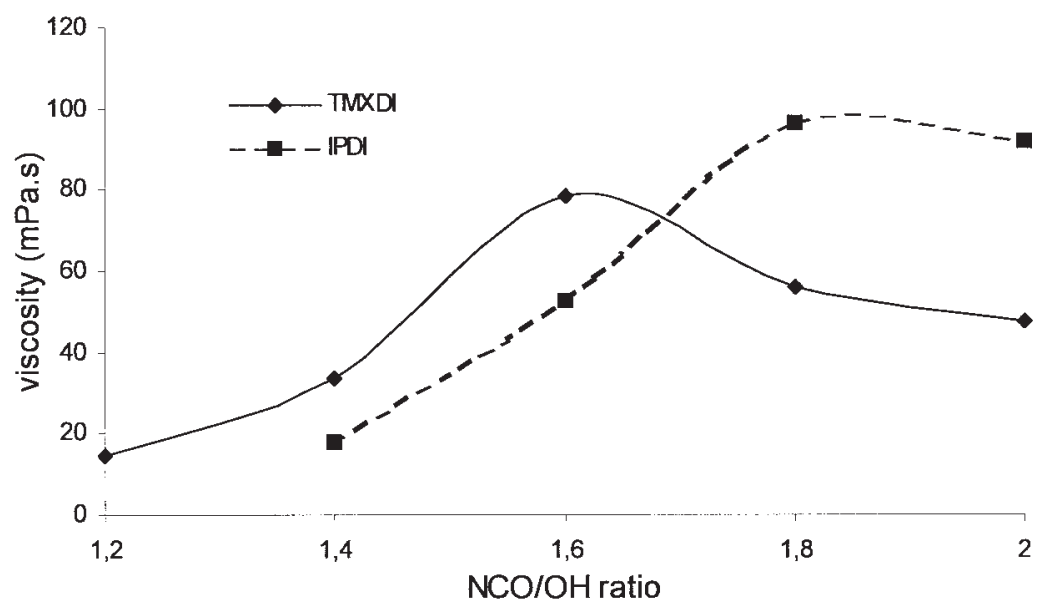

Figure 14 Effect of $[\mathrm{NCO}] /[\mathrm{OH}]$ ratio on the viscosity of the dispersions (see Table VIII).

their aqueous dispersions, because the liquid-solid interactions are enhanced by the increase in the specific area of the particles. The present results confirmed this trend, but only up to a certain [NCO]/ $[\mathrm{OH}]$ ratio, after which a decrease in viscosity was observed (Fig. 14). This decrease was less pronounced than the initial increase and was attributed to possible particle aggregation (not seen in the average size measurements because of the dilution required to carry them out) at the lower range of their size.

\section{CONCLUSION}

This investigation provided some useful indications on how to optimize the properties of polyurethaneurea dispersions. In particular, it showed that aliphatic diisocyanates like TMXDI and IPDI are much more appropriate than aromatic structures or symmetric aliphatic ones and that the $[\mathrm{NCO}] /[\mathrm{OH}]$ ratio plays a fundamental role and gives the most promising products in terms of small particle size in the dispersions and physical properties of the final polymer films, when it approaches a value of 2 . Work is in progress to assess the role of several macrodiols and the emulsifying agent.
The authors thank SICPA Co. for the financial and technological support generously attributed to this project.

\section{References}

1. Dietrich, D. Progr Organ Coat 1981, 9, 281.

2. Delpech, M. C.; Coutinho, F. M. B. Polym Test 2000, 19, 939.

3. Lee, S. Y.; Lee, J. S.; Kim, B. K. Polym Int 2000, 42, 67.

4. Lathinen, M..; Pinkfield, R. K.; Price, C. Polym Int 2003, 52, 1027.

5. Hourston, D. J.; Williams, G.; Satguru, R.; Padget, J. C.; Pears, D. J Appl Polym Sci 1999, 74, 556.

6. Satguru, R.; McMahon, J.; Padget, J. C.; Cogen, R. C. J Coat Technol 1994, 66, 47.

7. Wirpza, Z. Polyurethanes Chemistry, Technology and Applications; Ellis Horwood: London, 1993.

8. Aurenty, P.; Lanet, V.; Tessadro, A.; Gandini, A. Rev Sci Istrum 1997, 68, 1801.

9. Balkenende, R. H.; van de Boogaard, J. A. P.; Schloten, M.; Willard, N. P. Langmuir 1998, 14, 5907.

10. Durrieu, V.; Putaux, J-L.; Passas, R.; Gandini, A. Microsc Anal 2004, 18, 5.

11. Harris, J. R. Negative Staining Cryoelectron Microscopy: The Thin Films Techniques; Bios Scientific Publishers, Ltd.: Oxford, 1992.

12. Putaux, J. L.; Buléon, A.; Borsali, R.; Chanzy, H. Int J Biol Macromol 1999, 26, 145.

13. Klein, H. P.; Walz, G.; Schfheutle, M. A. U.S. Patent, 5 1997, 691, 425. 